\title{
Creation of nanosize defects in LiF crystals under 5- and 10-MeV Au ion irradiation at room temperature
}

\author{
A. Lushchik, ${ }^{1}$ Ch. Lushchik, ${ }^{1}$ K. Schwartz, ${ }^{2}$ E. Vasil'chenko, ${ }^{1}$ R. Papaleo, ${ }^{3}$ M. Sorokin, ${ }^{4}$ A. E. Volkov, ${ }^{4}$ R. Neumann, ${ }^{2}$ and \\ C. Trautmann ${ }^{2}$ \\ ${ }^{1}$ Institute of Physics, University of Tartu, Riia Street 142, 51014 Tartu, Estonia \\ ${ }^{2}$ Gesellschaft für Schwerionenforschung (GSI), Darmstadt, Planckstrasse 1, 64291 Darmstadt, Germany \\ ${ }^{3}$ Faculty of Physics-PUCRS, Avenida Ipiranga 6681, 960619-900 Porto Alegre, Rio Grande do Sul, Brazil \\ ${ }^{4}$ Russian Research Center, Kurchatov Institute, Kurchatov Square 1, 123182 Moscow, Russia
}

(Received 2 May 2007; published 14 August 2007)

\begin{abstract}
Investigation of radiation defects induced by the irradiation of $\mathrm{LiF}$ crystals with 5- or $10-\mathrm{MeV} \mathrm{Au}$ ions (fluences of $10^{11}-2 \times 10^{14}$ ions $/ \mathrm{cm}^{2}$; flux varies by 2 orders of magnitude) at room temperature has been performed using the methods of optical absorption and high-temperature $(400-750 \mathrm{~K})$ thermoactivation spectroscopy. The creation efficiency of color centers $\left(F, F_{2}, F_{3}, \ldots\right)$ and colloids drastically depends on both the fluence and ion flux (beam current). Besides impurity (magnesium) colloids with the absorption band peaked at 4.4-4.6 eV, the broad absorption band at $2.3-3.3 \mathrm{eV}$ related to intrinsic Li colloids is reliably distinguished. The creation efficiency of $\mathrm{Li}$ colloids by $5-\mathrm{MeV} \mathrm{Au}$ ions is lower than that by $10-\mathrm{MeV}$ ions, which form $\delta$ electrons with higher energies sufficient for the creation of cation excitons $(\sim 62 \mathrm{eV})$. The cation exciton decays, in turn, with the formation of a group of spatially close $F$ centers. At a high ion flux, the next bombarding ions hit the same crystal region with a small time delay (10-100 s) and also form, after similar intermediate processes, the groups of $F$ centers that participate in the formation of stable agglomerates of several $F_{3}$ or even more complex centers, which serve as stable (up to $620 \mathrm{~K}$ ) seeds for nanosize Li colloids. The peculiarities of the formation, enlargement, and annealing of intrinsic colloids in LiF crystals are considered, invoking a formal analog with the processes in photographic materials based on silver halides.
\end{abstract}

DOI: $10.1103 /$ PhysRevB.76.054114

PACS number(s): 61.80.Jh, 61.82.Ms, 61.72.-y, 68.55.Ln

\section{INTRODUCTION}

For a long time, wide-gap $\left(E_{g}=14.2 \mathrm{eV}\right) \mathrm{LiF}$ crystals have been used as optical windows for the vacuum ultraviolet spectral region and particularly as tissue-equivalent materials in personal dosimetry for $\gamma$ rays, electrons, and thermal neutrons. In this connection, electron-hole $(e-h)$ and excitonic processes responsible for prolonged storage of absorbed radiation energy have been thoroughly studied. A light sum of thermally stimulated luminescence (TSL) arising at the subsequent heating of an irradiated LiF sample in a temperature range of $300-550 \mathrm{~K}$ serves as a measure of a radiation dose. However, a reliable separation of the contribution of fast neutrons to the interaction of mixed fields of fast neutrons and $\gamma$ rays with LiF-based dosimetric materials has not been achieved yet.

It has long been established that radiation defects in solids can be formed due to elastic collisions of high-energy electrons, protons, and light ions with the atoms and/or ions of a crystal. This universal "knockout" or "impact" mechanism is connected with the displacement of anions or cations from regular lattice sites and the formation of vacancies $(v)$ and interstitials $(i)$ - the so-called $v-i$ pairs of Frenkel defects. At the same time, it is commonly accepted that besides this impact mechanism, the nonimpact mechanisms of Frenkel defect creation connected with the excitation and ionization of an electron subsystem by particles or quanta and the subsequent decay of self-trapped excitons or recombination of electrons with self-trapped holes ( $V_{K}$ centers) are also highly efficient in wide-gap alkali halide crystals (see Refs. 1-4, and references therein).
There are several studies of low-temperature $(5-300 \mathrm{~K})$ $e-h$ and $v-i$ processes in highly pure LiF single crystals (see Refs. 5-8, and references therein). By now, the excitonic and $e-h$ mechanisms of Frenkel pair creation have been revealed and thoroughly studied by means of synchrotron and thermoactivation spectroscopy methods in face-centered cubic LiF single crystals irradiated by photons or electrons. ${ }^{5-7}$ A Frenkel pair consists of an $F$ center (an electron in the field of an anion vacancy) and an $H$ center, which is a dihalide $\mathrm{F}_{2}{ }^{-}$ molecule located at one anion site and oriented along one of the $\langle 111\rangle$ directions. ${ }^{8}$

Radiation damage in alkali halides under heavy ion irradiation strongly depends on the energy loss, irradiation temperature, and dose (fluence). ${ }^{9-11}$ Irradiation with ions having an energy loss above a critical threshold of $6-10 \mathrm{keV} / \mathrm{nm}$ leads to a complex track structure with nanosize damage in the central part of the track (core) and color centers in a larger damage zone of several tens of nanometers (halo) around the ion path. ${ }^{12-14}$ The irradiation of LiF crystals by $\sim 2.5 \mathrm{GeV}$ heavy ions (Au, $\mathrm{U}$, etc.) induces an abundance of $F$ centers in a thin layer (ion range is $R \approx 90 \mu \mathrm{m}$ ). In the case of high irradiation fluences $\left(\sim 10^{12}\right.$ ions $\left./ \mathrm{cm}^{2}\right)$, the optical density at $5 \mathrm{eV}$ ( $F$-center absorption band) exceeds $D=3$ and conventional absorption measurements are inapplicable. On the other hand, the penetration depth of the ions with the kinetic energy of 5-10 MeV significantly decreases $(R=1-2 \mu \mathrm{m})$ and conventional absorption spectrometers can be used for the samples irradiated with fluences of up to $10^{14}$ ions $/ \mathrm{cm}^{2}$. Highly sensitive luminescent methods can be efficiently applied at such ion fluences as well.

There are no detailed studies of defect creation in ionic crystals under irradiation with $5-$ and $10-\mathrm{MeV}$ ions, includ- 
TABLE I. ${ }^{198} \mathrm{Au}$ ion irradiation parameters in LiF crystals according to SRIM 2003 (Ref. 15).

\begin{tabular}{lcccc}
\hline \hline Energy & Range $R$ & \multicolumn{2}{c}{ Mean energy loss, $S(\mathrm{keV} / \mathrm{nm})$} & $\begin{array}{c}\text { Ratio } \\
(\mu \mathrm{m})\end{array}$ \\
\cline { 3 - 4 } & $S_{\text {elec }}$ & $S_{\text {nuc }}$ & $(\%)$ \\
\hline 5 & 1.14 & 1.7 & 2.6 & 60 \\
10 & 2.34 & 2.1 & 2.0 & 48 \\
2187 & 92.0 & 23.8 & 0.02 & 0.1 \\
\hline \hline
\end{tabular}

ing $\mathrm{Au}$. These ions have different irradiation parameters in comparison with GeV ions. ${ }^{15-18}$ For 5- and $10-\mathrm{MeV}$ ions, the energy of $\delta$ electrons is limited to that of $50-110 \mathrm{eV}$ and the free path of such low-energy $\delta$ electrons is only about $1 \mathrm{~nm}$, i.e., by orders of magnitude lower than that for $\mathrm{GeV}$ ions. Therefore, a different energy spectrum and spatial distribution of the secondary electrons around the ion path, which influence the defect creation mechanism, are produced. For 5-10 MeV Au ions, the ratio of a mean nuclear energy loss (elastic collisions) to the electronic energy loss is much higher than that for $\mathrm{GeV}$ ions and ion displacements can influence the defect creation (see Table I and Sec. IV B for details). The lattice ions $\left(\mathrm{Li}^{+}, \mathrm{F}^{-}\right)$displaced by irradiation with 5-10 MeV Au ions have a kinetic energy of several hundred $\mathrm{eV}$, and before localization, these hot interstitials form $\delta$ electrons, which, according to the spectra of electron energy losses, are able to create longitudinal anion excitons $(\sim 13.5 \mathrm{eV})$, separated electrons and holes, as well as plasmons $^{19}(\sim 25 \mathrm{eV})$ and cation excitons $(\sim 62 \mathrm{eV}) .{ }^{20}$

The small ion range of 5-10 MeV Au ions in LiF crystals (Table I) determines a much higher volume concentration of $F$ centers than for $\mathrm{GeV}$ ions at the same total number of primary created defects. This leads to a different interaction of the created $F$ and $H$ centers and their stronger aggregation $\left(F_{2}, F_{3}, \ldots, H_{2}, \ldots\right)$. It turns out that besides $F_{n}$ centers, Au ions with a kinetic energy of 5-10 $\mathrm{MeV}$ cause the appearance of a broad absorption band at 2.5-3.5 eV, which can be ascribed to nanosize lithium colloids (see Sec. IV).

In the present study, radiation damage in LiF crystals under irradiation with 5-10 MeV heavy ions at fluences of $10^{12}-2 \times 10^{14}$ ions $/ \mathrm{cm}^{2}$ and at beam current (ion flux) in a wide range of 1-200 nA has been investigated using luminescent and direct absorption methods. Of particular interest are the peculiarities of the processes of the creation and thermal annealing of defects under extreme irradiation conditions (high fluence and flux) when the probability of repeated interaction of heavy ions with the crystal regions already containing ion tracks (formed at an earlier stage of irradiation) is high. Under such irradiation conditions, one can expect the creation of nanosize defects significantly different from both Frenkel pairs and large-scale (microsize) defect aggregates. The mechanisms of the creation and annealing of nanosize defects have been clarified using various thermoactivation spectroscopy methods (see, e.g., Refs. 2 and 21, and references therein).

\section{EXPERIMENT}

All experiments were performed on nominally pure $\mathrm{LiF}$ single crystals grown from the melt in an inert atmosphere (from Korth Kristalle, Germany). The platelets of 10 $\times 5 \mathrm{~mm}^{2}$ with the thickness of $0.5 \mathrm{~mm}$ were cleaved from a crystal block along one of the (100) planes. The analysis of the photo- and cathodoluminescence spectra at $6-10 \mathrm{~K}$ as well as of $K_{\alpha} \mathrm{X}$-ray emission allowed us to conclude that our LiF samples contain about $20 \mathrm{ppm}$ of $\mathrm{Mg}^{2+}$ and $\mathrm{Na}^{+}$impurity ions.

Crystals were irradiated at room temperature (RT) perpendicular to the (100) plane at the Tandetron $3 \mathrm{MV}$ accelerator in Porto Alegre with 5-MeV Au${ }^{+2}$ and $10-\mathrm{MeV} \mathrm{Au}^{+4}$ ions at fluences of $\Phi=10^{12}-10^{15}$ ions $/ \mathrm{cm}^{2}$. The ion beam density was varied between 1 and $200 \mathrm{nA} / \mathrm{cm}^{2}$ (hereinafter only the current value will be used). By taking into account the charge state of the ions $(k)$, the flux $\varphi$ (ions $\mathrm{cm}^{-2} \mathrm{~s}^{-1}$ ) was equal to

$$
\varphi\left(\text { ions } \mathrm{cm}^{-2} \mathrm{~s}^{-1}\right)=6.24 \times 10^{9} i_{\text {beam }}(\mathrm{nA}) k^{-1},
$$

where $i_{\text {beam }}$ is the ion beam current in nanoamperes. For 5-MeV and 10-MeV Au ions, $k$ equals 2 and 4, respectively. The accuracy of the beam current was $\pm 0.1 \mathrm{nA}$. In order to compare low-energy $(5-10 \mathrm{MeV})$ and $\mathrm{GeV}$ ion irradiations, the LiF samples were irradiated at the UNILAC linear accelerator of the GSI Darmstadt with 2187-MeV Au ions at a fluence of $\Phi=4 \times 10^{10} \mathrm{ions} / \mathrm{cm}^{2}$ with a flux $\varphi$ $\sim 10^{8}$ ions $\mathrm{cm}^{-2} \mathrm{~s}^{-1}$; the accuracy of the fluence was $\pm 20 \%$ (more details in Ref. 11). The range $R$ of all ions was smaller than the thickness of the samples.

The spectra of induced optical absorption (IOA) were measured in the spectral region of $6.5-1.5 \mathrm{eV}$ $(190-850 \mathrm{~nm})$ at RT using double-beam spectrometers ATI Unicam UV4 or JASCO V-540. In order to analyze the real changes of optical absorption (optical density) induced by ion irradiation, the absorption of a nonirradiated sample was subtracted from the presented IOA spectra. The most significant electron color centers are $F$ and $F_{2}$ centers, with the absorption maxima at $4.95 \mathrm{eV}(250 \mathrm{~nm})$ and $2.79 \mathrm{eV}$ $(445 \mathrm{~nm})$, respectively. ${ }^{22}$ The complementary trihalide $\mathrm{F}_{3}{ }^{-}$ centers, stable at RT, have the absorption band in the vacuum ultraviolet spectral region at $10.8 \mathrm{eV}(114 \mathrm{~nm}))^{7,23}$

The number of the created $F$ centers $\left(n_{F}\right.$ in $\left.\mathrm{cm}^{-2}\right)$ in $\mathrm{LiF}$ was determined by the Smakula-Dexter formula: ${ }^{11,14}$

$$
n_{F}=9.48 \times 10^{15} D_{F}
$$

where $D_{F}$ is the optical density at the absorption maximum of $F$ centers. The average volume concentration of the color centers $N_{F}\left(\right.$ in $\left.\mathrm{cm}^{-3}\right)$ can be estimated as $N_{F}=n_{F} / R$, where $R$ is the ion range (Table I).

All curves of high-temperature TSL (300-750 K) were measured at the heating of previously irradiated samples with a constant rate of $\beta=2.86 \mathrm{~K} \mathrm{~s}^{-1}$ in the atmosphere of flowing nitrogen, using a System 310 TLD reader. TSL was registered for integral signal using an optical filter with a transmission at $1.7-3.7 \mathrm{eV}(335-730 \mathrm{~nm})$. The thermal background emission from the heater was subtracted for the temperature range of $600-750 \mathrm{~K}$. 


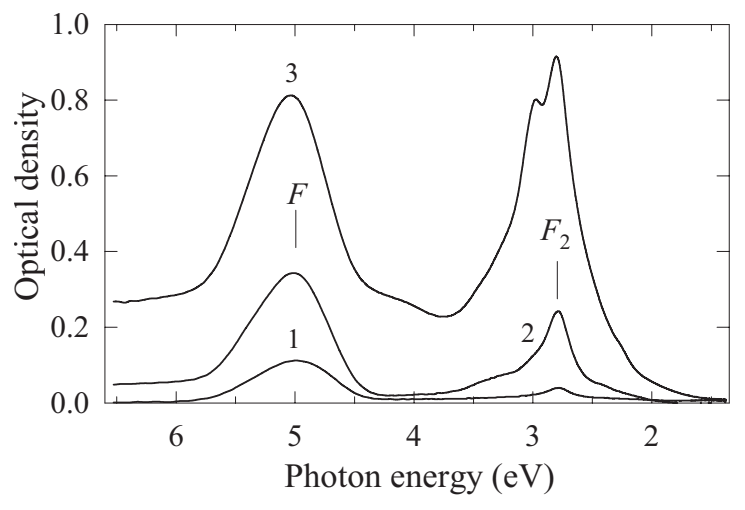

FIG. 1. The absorption spectra measured for LiF crystals irradiated at $300 \mathrm{~K}$ by $5-\mathrm{MeV} \mathrm{Au}$ ions at fluences of $10^{12} \mathrm{ions} / \mathrm{cm}^{2}$ (curve 1), $10^{13}$ ions $/ \mathrm{cm}^{2}$ (curve 2), and $10^{14}$ ions $/ \mathrm{cm}^{2}$ (curve 3 ). The spectra are measured at RT, the absorption of nonirradiated sample is subtracted.

\section{EXPERIMENTAL RESULTS}

\section{A. Dependence of defect creation by 5-MeV Au ions on the irradiation fluence and flux}

The spectra of IOA have been measured in the region of $1.5-6.5 \mathrm{eV}$ for $\mathrm{LiF}$ crystals irradiated at $\mathrm{RT}$ with various fluences $\left(\Phi=10^{11}-2 \times 10^{14}\right.$ ions $\left./ \mathrm{cm}^{2}\right)$ of $5-\mathrm{MeV}$ Au ions. At such irradiation conditions, an average distance $d$ $=2(\pi \Phi)^{-1 / 2}$ between ion tracks at the (100) crystal plane varies from 36 to $0.8 \mathrm{~nm}$.

Figure 1 presents the absorption spectra of LiF measured for three fluences of $5-\mathrm{MeV} \mathrm{Au}$ ions $\left(10^{12}, 10^{13}\right.$, and $10^{14}$ ions $/ \mathrm{cm}^{2}$ ) when $d$ is equal to $11,3.6$, or $1.1 \mathrm{~nm}$, respectively. $F$ centers (maximum of the absorption band at $4.95 \mathrm{eV}$ and bandwidth of $\sim 0.8 \mathrm{eV}$ ) dominate in the spectrum of ion-induced absorption at $\Phi=10^{12} \mathrm{ions} / \mathrm{cm}^{2}$. A weak absorption band peaked at $2.79 \mathrm{eV}$ and related to $F_{2}$ centers can also be detected under such irradiation conditions when there is practically no interaction between the defects created by different ions. At a higher fluence, $\Phi=10^{13}$ ions $/ \mathrm{cm}^{2}$ $(d=3.6 \mathrm{~nm})$, the intensity of $F$ band increases by a factor of 3 and that of $F_{2}$ centers even more. An additional absorption at the wings of $F_{2}$ band is observed as well. The subsequent rise of the beam fluence from $10^{13}$ to $10^{14}$ ions $/ \mathrm{cm}^{2}$ $(d=1.1 \mathrm{~nm})$ causes a relatively lower growth of $F$ band (by a factor of $\sim 1.6$ ), the maximum of which is shifted to $5.05 \mathrm{eV}$ due to the distortion of single $F$ centers by neighboring defects, and the appearance of intense broadband absorption (pedestal) at $4.0-6.5 \mathrm{eV}$. At $\Phi=10^{14}$ ions $/ \mathrm{cm}^{2}$, the intensity of the complex absorption bands at 2.0-3.5 eV, with a sharp peak $(\sim 2.8 \mathrm{eV})$ related to distorted $F_{2}$ and $F_{3}{ }^{+}$(Ref. 22) centers, already exceeds the absorption intensity at $5 \mathrm{eV}$.

A detailed study of the dependence of the $F$ absorption band on the fluence of 5-MeV gold ions shows that the maximum number of $F$ centers, $N_{F} \approx 6 \times 10^{19} \mathrm{~cm}^{-3}$, can be created at $\Phi=8 \times 10^{13}-10^{14}$ ions $/ \mathrm{cm}^{2}$, while a decrease of the $F$-band intensity takes place already at $2 \times 10^{14}$ ions $/ \mathrm{cm}^{2}$.

Unexpectedly, it turned out that in the case of a powerful ion beam, the efficiency of $F$-center creation depends on

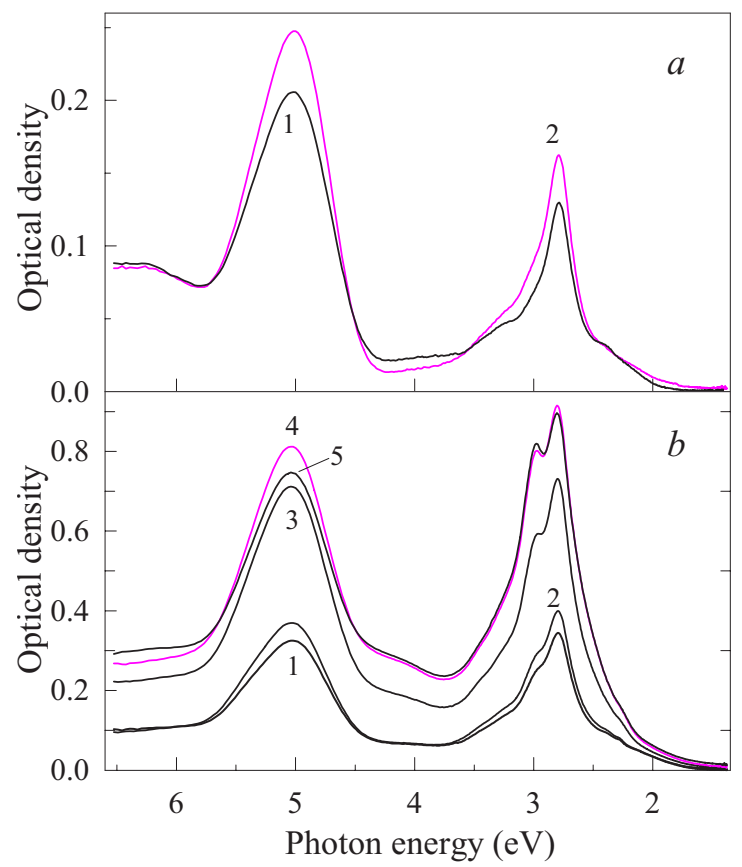

FIG. 2. (Color online) The absorption spectra of LiF crystals irradiated at $300 \mathrm{~K}$ by $5-\mathrm{MeV} \mathrm{Au}$ ions at fluence of (a) $5 \times 10^{12}$ ions $/ \mathrm{cm}^{2}$ or (b) $10^{14}$ ions $/ \mathrm{cm}^{2}$. Ion beam current equals $1 \mathrm{nA}$ [curve 1(a)] and $200 \mathrm{nA}$ [curve 2(a)]; $5 \mathrm{nA}$ [curve 1(b)], $10 \mathrm{nA}$ [curve 2(b)], $50 \mathrm{nA}$ [curve 3(b)], $120 \mathrm{nA}$ [curve 4(b)], and $200 \mathrm{nA}$ [curve 5(b)].

both the fluence and the flux used to reach this fluence. Figure 2 shows the IOA spectra measured for LiF crystals irradiated by $5-\mathrm{MeV}$ gold ions with two different fluences. To accumulate the prescribed $\Phi_{1}=5 \times 10^{12} \mathrm{ions} / \mathrm{cm}^{2}$ or $\Phi_{2}=10^{14}$ ions $/ \mathrm{cm}^{2}$, the ion beam, current was varied from 1 to $200 \mathrm{nA}$ or from 5 to $200 \mathrm{nA}$, respectively (flux $\varphi$ is proportional to $\left.i_{\text {beam }}\right)$. At low fluence $\Phi_{1}(d=5.1 \mathrm{~nm})$, the rise of $\varphi$ practically does not influence the IOA spectra. Similarly, the spectra only slightly depend on the increase of $\varphi$ from 5 to $10 \mathrm{nA}$ at 20 times higher fluence $\Phi_{2}$ $(d=1.1 \mathrm{~nm})$. However, the subsequent rise of the beam current to $50 \mathrm{nA}$ and, especially, to $120 \mathrm{nA}$ causes a sharp enhancement of IOA, while IOA slightly decreases after ion irradiation with $i_{\text {beam }}=200 \mathrm{nA}$.

This effect of the drastic increase of IOA with increasing $i_{\text {beam }}$ from 5-10 nA to $50-200 \mathrm{nA}$ at $\Phi_{2}=10^{14}$ ions $/ \mathrm{cm}^{2}$ will be discussed in detail in Sec. IV. However, to gain a better understanding of the logic of the further presentation of our experimental results, it is useful to stress preliminarily the following circumstances. The prescribed fluence $\Phi_{2}$ was accumulated within very different time intervals: about $107 \mathrm{~min}$ at $i_{\text {beam }}=5 \mathrm{nA}$ and only $160 \mathrm{~s}$ at $i_{\text {beam }}=200 \mathrm{nA}$. The reciprocity law (the intensity $\times$ duration of irradiation) failure at low intensities was revealed long ago in photographic materials (e.g., in $\mathrm{AgBr}$ :I emulsions ${ }^{24}$ ) and convincingly interpreted as the necessity to stabilize at RT a group of at least three single Frenkel defects formed during irradiation. ${ }^{24-26}$ In AgBr:I, such stable defect associations are formed under conditions of sufficiently high fluxes or if an excited photon $(\sim 10 \mathrm{eV})$ simultaneously creates three $e-h$ pairs. It was 
shown earlier ${ }^{27,28}$ that especially favorable conditions for the creation of stable $F$ centers and complementary defect associations $\left(H-H\right.$ or $H-V_{K}$ pairs) at RT arise at the selective irradiation of $\mathrm{KBr}$ and $\mathrm{KCl}$ crystals by $20-30 \mathrm{eV}$ photons, the energy of each of which is sufficient to form spatially correlated $e-h$ pair and a secondary anion exciton (i.e., under conditions of a high local density of electronic excitations). Certainly, the situation is more complicated at the irradiation of $\mathrm{LiF}$ by $5-\mathrm{MeV} \mathrm{Au}$ ion beam with high values of $\Phi$ and $\varphi$. Besides $F$ and $F_{2}$ absorption bands, the broad IOA (pedestals) related to defect aggregates is observed in the absorption spectra of LiF (see Fig. 2).

The methods of thermoactivation spectroscopy, when various optical characteristics are measured during heating (in different regimes) of the irradiated ionic crystal (see, e.g., Refs. 2 and 21 for details), have been applied to separate the contributions of different defects and/or aggregates. The ionirradiated LiF crystal was heated with a constant rate of $\beta=2.86 \mathrm{~K} \mathrm{~s}^{-1}$ to $513 \mathrm{~K}$ and rapidly $(\sim 10 \mathrm{~s})$ cooled down to RT, and the spectrum of IOA was measured at RT. Thereafter, the sample was preheated up to $613 \mathrm{~K}$ and cooled down, and the absorption spectrum was registered once more at RT. For the third time, the irradiated sample was preheated to the highest available temperature of $753 \mathrm{~K}$ and, again, the IOA spectrum was measured at RT (Figs. 3-6). During every heating, the integral TSL was measured as well (these TSL curves are presented in Figs. 7 and 8 and will be discussed later).

Figure 3 presents the IOA spectra measured for the $\mathrm{LiF}$ irradiated at RT by $5-\mathrm{MeV}$ Au ions $\left(\Phi=10^{14}\right.$ ions $/ \mathrm{cm}^{2}$, $i_{\text {beam }}=120 \mathrm{nA}$ ) and after an additional preheating of this sample to a prescribed temperature. Figure 3 also shows the decrease of IOA caused by the preheating of ionirradiated $\mathrm{LiF}$ crystal to $513 \mathrm{~K}$ or intermediate preheating $513 \rightarrow 613 \mathrm{~K}, 613 \rightarrow 753 \mathrm{~K}$. All absorption spectra are measured at RT. According to these difference spectra, the preheating to $513 \mathrm{~K}$ causes a sharp decrease of the number of $F$ and $F_{2}$ centers (absorption bands at 5 and $2.8 \mathrm{eV}$, respectively), while the rise of the optical density takes place at $2.9-4.6 \mathrm{eV}$. A subsequent preheating to $613 \mathrm{~K}$ causes practically a total destruction of the remaining $F$ and $F_{2}$ centers and the complicated transformations of IOA at $2.2-4.8 \mathrm{eV}$. Preheating from 613 to $753 \mathrm{~K}$ provides a partial annealing of a broad absorption band (pedestal) at $3.8-4.9 \mathrm{eV}$, while only a weak maximum at $3.2 \mathrm{eV}$ remains from a broad band at $2.3-3.3 \mathrm{eV}$. The total annealing of IOA at $2.3-3.3 \mathrm{eV}$ can be achieved by repeated heatings of the sample to $753 \mathrm{~K}$ (for technical reasons, the crystal can be kept at this high temperature only for a short time). The total annealing of the $3.8-4.9 \mathrm{eV}$ band takes place at an even higher temperature $(\sim 800 \mathrm{~K}$, see Sec. IV A for details).

In $\mathrm{LiF}$ irradiated by $5-\mathrm{MeV}$ Au ions with $\Phi$ $=5 \times 10^{12}$ ions $/ \mathrm{cm}^{2}$, the absorption bands of $F$ and $F_{2}$ centers are clearly observed even in the case of a high flux, $i_{\text {beam }}=120 \mathrm{nA}$ (see Fig. 4). In addition, the weak absorption related to $F_{3}(3.26 \mathrm{eV})$ and $F_{4}$ centers $(2.26$ and $2.37 \mathrm{eV})$ (Ref. 29) is registered at both wings of the $F_{2}$ band. However, in contrast to the case presented in Fig. 3 $\left(\Phi=10^{14} \mathrm{ions} / \mathrm{cm}^{2}, i_{\text {beam }}=120 \mathrm{nA}\right)$, the IOA at $4.3-4.8 \mathrm{eV}$ and $1.8-3.5 \mathrm{eV}$ is rather weak. The drastic annealing of the

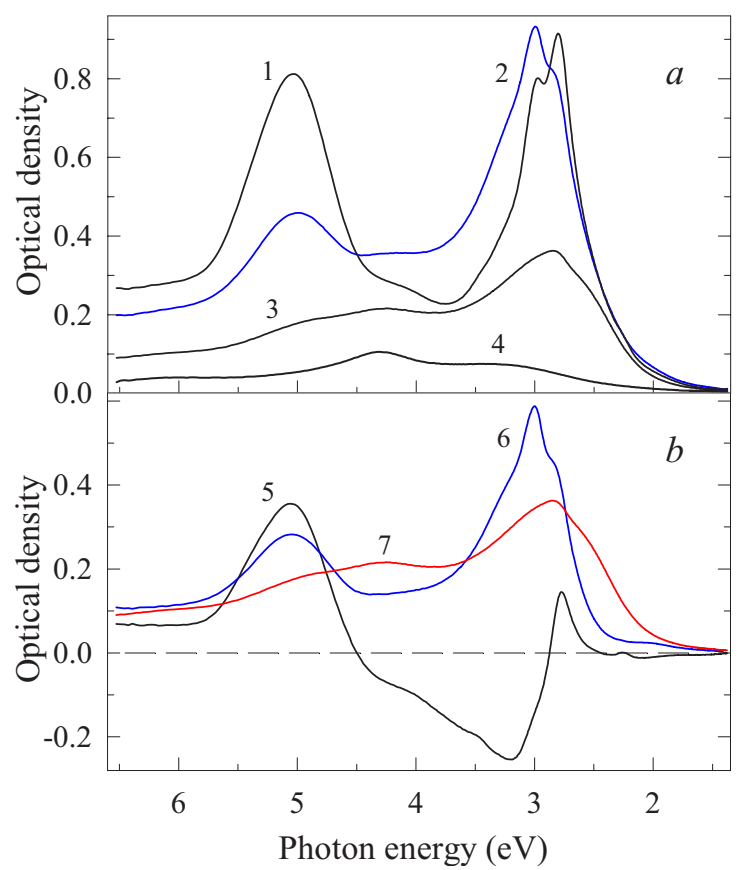

FIG. 3. (Color online) (a) The absorption spectra of a LiF crystal irradiated by $5-\mathrm{MeV} \mathrm{Au}$ ions ions $\left(\Phi=10^{14}\right.$ ions $/ \mathrm{cm}^{2}$, $\left.i_{\text {beam }}=120 \mathrm{nA}\right)$ at $300 \mathrm{~K}$. The spectra are measured at RT after irradiation (curve 1) or additional preheating to $513 \mathrm{~K}$ (curve 2), $613 \mathrm{~K}$ (curve 3), and $753 \mathrm{~K}$ (curve 4). (b) Decrease (difference spectra) of radiation-induced absorption caused by a preheating of the irradiated crystal to $513 \mathrm{~K}$ (curve 5 , obtained by a subtraction of curve 2 from curve 1 ) or an intermediate preheating $513 \rightarrow 613 \mathrm{~K}$ (curve 6, subtraction of curve 3 from curve 2) and $613 \rightarrow 753 \mathrm{~K}$ (curve 7 , subtraction of curve 4 from curve 3 ).

absorption at $1.8-3.5 \mathrm{eV}$ takes place already after heating to $613 \mathrm{~K}$, and the absorption spectrum of a virgin sample (before ion irradiation) can be practically restored by the preheating of the irradiated sample to $753 \mathrm{~K}$ (see Fig. 3). For $5-\mathrm{MeV}$ Au ions at $\Phi=5 \times 10^{12}$ ions $/ \mathrm{cm}^{2}$, the broadband IOA at $4.4 \mathrm{eV}$ and, especially, at $2.4-3.6 \mathrm{eV}$ is rather low. Both high fluence and high flux are needed to induce this broad absorption band (see Fig. 3).

\section{B. Dependence of defect creation on the energy of gold ions}

The broadband IOA of $\mathrm{LiF}$ crystals irradiated with $10-\mathrm{MeV} \mathrm{Au}$ ions (high values of $\varphi$ and $\Phi$ ) has been investigated in an effort to elucidate the elementary creation mechanisms of the defects responsible for these absorption bands. The range $(R=2.34 \mu \mathrm{m})$ of gold ions with such kinetic energy is twice as high as that for $5-\mathrm{MeV}$ ions, while the contribution of elastic collisions to total energy losses is by a factor of 1.3 lower (see Table I). It seemed reasonable to suppose that, in contrast to $5-\mathrm{MeV} \mathrm{Au}$ ions, the energy of $\delta$ electrons formed by $10-\mathrm{MeV}$ ions is sufficient not only for the creation of $e-h$ pairs and anion excitons but for the excitation of lithium ions (energy of cation excitons is $\sim 62 \mathrm{eV}$ ) as well.

Figure 5(a) shows the spectra of IOA for LiF crystals irradiated with $10-\mathrm{MeV}$ gold ions $\left(\Phi_{1}=2 \times 10^{14} \mathrm{ions} / \mathrm{cm}^{2}\right.$ 


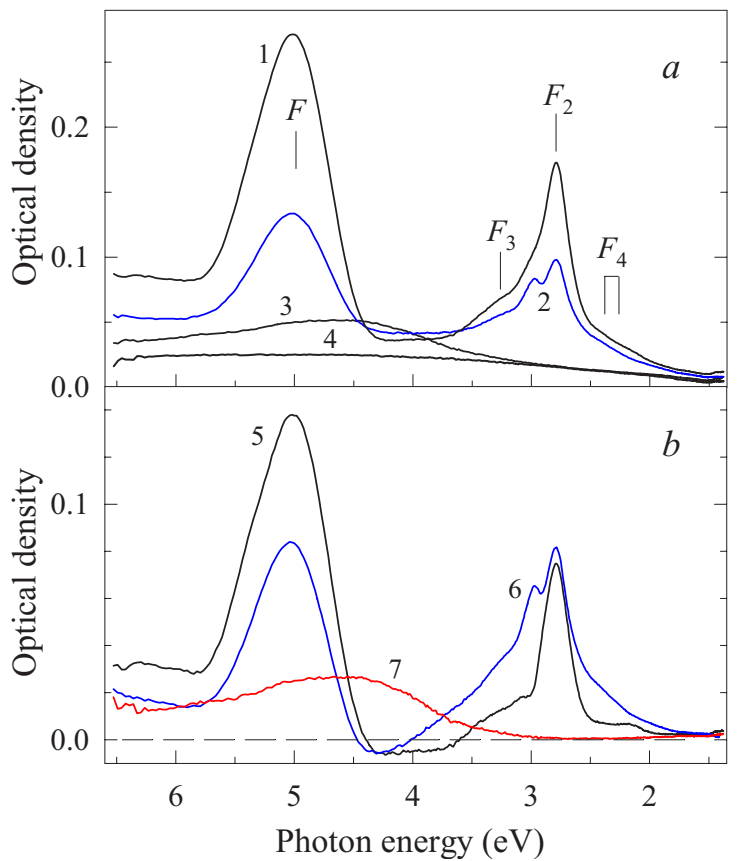

FIG. 4. (Color online) (a) The absorption spectra of a LiF crystal irradiated by $5-\mathrm{MeV} \mathrm{Au}$ ions ions $\left(\Phi=5 \times 10^{12}\right.$ ions $/ \mathrm{cm}^{2}$, $\left.i_{\text {beam }}=120 \mathrm{nA}\right)$ at $300 \mathrm{~K}$. The spectra are measured at RT after irradiation (curve 1) or additional preheating to $513 \mathrm{~K}$ (curve 2), $613 \mathrm{~K}$ (curve 3), and $753 \mathrm{~K}$ (curve 4). (b) Decrease of radiationinduced absorption caused by a preheating of the irradiated crystal to $513 \mathrm{~K}$ (curve 5 ) or an intermediate preheating $513 \rightarrow 613 \mathrm{~K}$ (curve 6 ) and $613 \rightarrow 753 \mathrm{~K}$ (curve 7 ).

and $\Phi_{2}=8 \times 10^{13}$ ions $/ \mathrm{cm}^{2}$ ) as well as the difference of IOA caused by the irradiation with $\Phi_{1}$ or $\Phi_{2}$. The decrease of the distance between ion impacts $d$ from 1.3 to $0.8 \mu \mathrm{m}$ and the enhancement of undoubtedly multiple covering of the (100) irradiated plane by colored regions led to the drastic rise of IOA at $2.2-3.8 \mathrm{eV}$ and to a moderate increase of radiationinduced absorption at $3.8-4.6 \mathrm{eV}$. In the case of a lower fluence $\Phi_{2}$, the absorption band connected with $F$ centers is clearly observed, while its maximum is slightly shifted and the band is strongly broadened with respect to the case of single $F$ centers. The broadening is caused by the presence of another radiation defect spatially close to an $F$ center. The rise of the fluence by a factor of $2.5\left(\Phi_{2} \rightarrow \Phi_{1}\right)$ does not increase the number of $F$ centers [see difference spectrum in Fig. 5(a)], while it causes the enhancement of absorption at 2.3-4.8 eV. Figure 5(b) depicts the IOA spectra (and the difference one) for LiF crystals irradiated by $10-\mathrm{MeV}$ or $5-\mathrm{MeV}$ gold ions with the same fluence $\Phi=2 \times 10^{14}$ ions $/ \mathrm{cm}^{2} \quad\left(i_{\text {beam }}=120 \mathrm{nA}\right)$. Low-energy broadband IOA, ascribed to nanosize lithium colloids (see Refs. 29 and 30 and Sec. IV for details), is especially intense in the sample irradiated by $10-\mathrm{MeV}$ ions. At $\Phi=2 \times 10^{14}$ ions $/ \mathrm{cm}^{2}$, the volume concentration of $F$ centers determined by the Smakula-Dexter formula equals $N_{F}=6 \times 10^{19} \mathrm{~cm}^{-3}$ for $5-\mathrm{MeV} \mathrm{Au}$ ions and is lower for $10-\mathrm{MeV}$ ions, $N_{F}=4 \times 10^{19} \mathrm{~cm}^{-3}$. It was taken into account that the range $R$ for $5-\mathrm{MeV}$ gold ions is twice as low as that for $10-\mathrm{MeV} \mathrm{Au}$ ions (1.14 and $2.34 \mu \mathrm{m}$, respectively). The

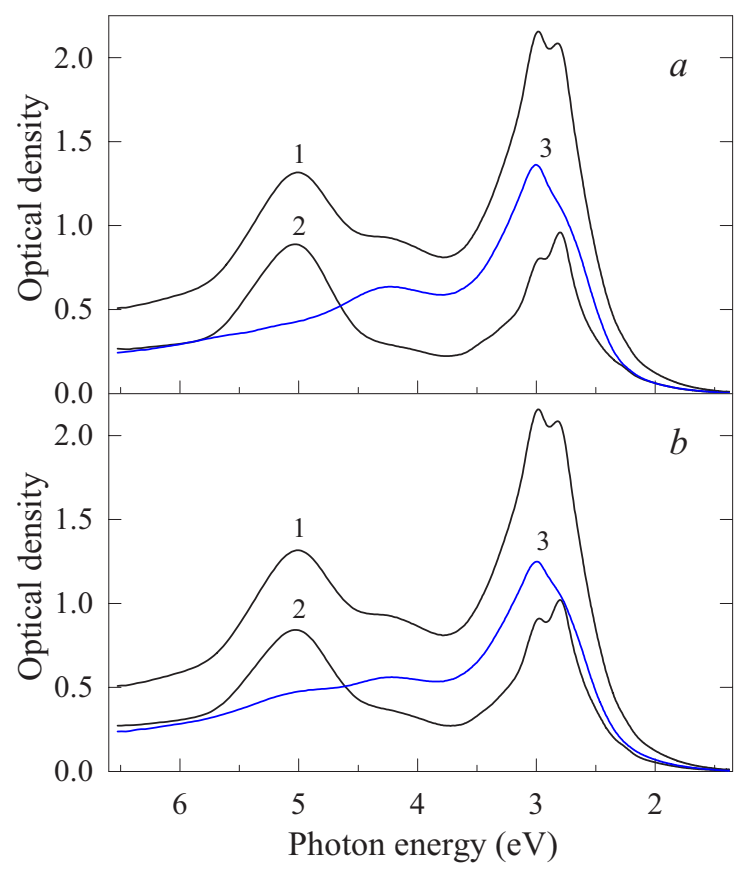

FIG. 5. (Color online) The absorption spectra of LiF irradiated by $10-\mathrm{MeV} \mathrm{Au}$ ions with $\Phi=2 \times 10^{14}$ ions $/ \mathrm{cm}^{2}$ [curves 1 (a) and 1(b)], $\Phi=8 \times 10^{13}$ ions $/ \mathrm{cm}^{2}$ [curve 2(a)], and by $5-\mathrm{MeV}$ gold ions with $\Phi=2 \times 10^{14}$ ions $/ \mathrm{cm}^{2}$ [curve 2(b)] at $300 \mathrm{~K}$. Curve 3 (difference spectra) is obtained by a subtraction of curve 2 from curve 1 .

energy of $10-\mathrm{MeV}$ gold ions is efficiently used for the formation of the radiation defects responsible for a broadband absorption at $2.3-3.4 \mathrm{eV}$. This IOA drastically increases with a rise of $\Phi$ from $8 \times 10^{13} \mathrm{Au} / \mathrm{cm}^{2}$ to 2 $\times 10^{14}$ ions $/ \mathrm{cm}^{2}$ and, in our opinion (see Sec. IV A), is attributed to intrinsic lithium colloids. It should be pointed out that the radiation defects created in highly perfect $\mathrm{LiF}$ single crystals under irradiation by heavy ions with $R$ $=1.14-2.34 \mu \mathrm{m}$ are mainly formed in the crystal bulk and not in a near-surface layer (with a thickness of several nanometers). Contrary to semiconductors and alkali iodides, radiation-induced excitons and holes in $\mathrm{LiF}$ rapidly lose their mobility and undergo self-trapping (see, e.g., Refs. 6 and 8). The following decay of self-trapping electronic excitations causes mainly the formation of defects situated far from the surface.

The optical characteristics of the LiF crystals irradiated by $\mathrm{GeV}$ gold ions drastically differ from those presented in Fig. 5. Figure 6(a) shows the IOA spectrum measured at $\mathrm{RT}$ for $\mathrm{LiF}$ irradiated by $2.187-\mathrm{GeV} \mathrm{Au}$ ions $\left(\Phi=4 \times 10^{10}\right.$ ions $\left./ \mathrm{cm}^{2}\right)$. According to Table I, in this case $R=92.0 \mu \mathrm{m}$ and the energy losses are almost entirely $(\sim 99.9 \%)$ due to an ion energy transfer to the electron subsystem. For the used irradiation conditions $d=56.5 \mathrm{~nm}$, the range of $\delta$ electrons with an energy of about $10 \mathrm{keV}$ is several hundreds of nanometers, and only a weak interaction between single ion tracks takes place. The $F$ band (with maximum $4.96 \mathrm{eV}$ and half-width $0.79, N_{F}=4 \times 10^{18} \mathrm{~cm}^{-3}$ ) dominates the spectrum, there is practically no IOA at $3.5-4.3 \mathrm{eV}$, and the absorption of $F_{2}$ centers $(2.79 \mathrm{eV})$ is clearly observed. The preheating of the irradiated sample to 


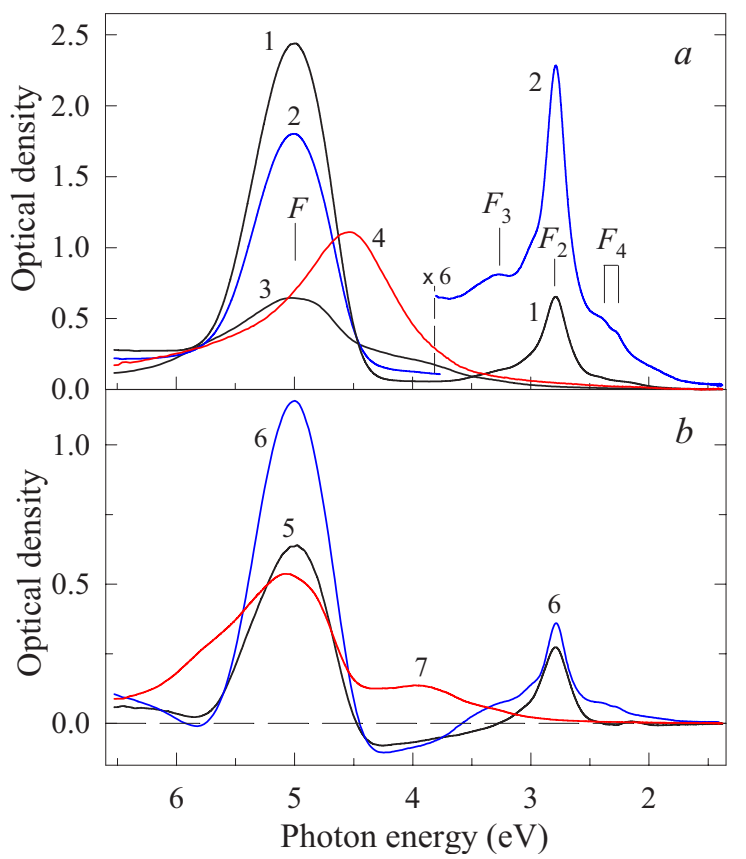

FIG. 6. (Color online) (a) The absorption spectra of a LiF crystal irradiated by $2.187-\mathrm{GeV} \mathrm{Au}$ ions $\left(\Phi=4 \times 10^{10}\right.$ ions $\left./ \mathrm{cm}^{2}\right)$ at $300 \mathrm{~K}$. The spectra are measured at RT after irradiation (curve 1) or additional preheating to $513 \mathrm{~K}$ (curve 2), $613 \mathrm{~K}$ (curve 3), and $753 \mathrm{~K}$ (curve 4). Curve 4 and a low-energy part of curve 3 are multiplied by a factor of 6. (b) Decrease of radiation-induced absorption caused by a preheating of the irradiated crystal to $513 \mathrm{~K}$ (curve 5) or an intermediate preheating $513 \rightarrow 613 \mathrm{~K}$ (curve 6) and $613 \rightarrow 753 \mathrm{~K}$ (curve 7 ).

$513 \mathrm{~K}$ causes the decrease of the number of $F$ and $F_{2}$ centers [see difference spectrum in Fig. 6(b)]. The bands connected with $F_{3}$ and $F_{4}$ centers are clearly recognized at the wings of the partly remaining $F_{2}$ band and the enhancement of IOA at $3.3-4.5 \mathrm{eV}$ is observed in the spectrum of the sample preheated to $513 \mathrm{~K}$. The intermediate preheating $513 \rightarrow 613 \mathrm{~K}$ results in the annealing of the main part of $F$ centers and a significant part of $F_{2}, F_{3}$, and $F_{4}$ centers, while a weak broadband IOA at 3.5-4.8 eV still survives [Fig. 6(a), curve 4]. A weak broadband IOA with the maximum at $4.45 \mathrm{eV}$ is still observed in the sample preheated to $753 \mathrm{~K}$. According to several authors (see Refs. 30 and 31 and Sec. IV A), this band is caused by the presence of $\mathrm{Mg}^{2+}$ impurity ions in nominally pure LiF crystals and corresponds to impurity (magnesium) colloids. The formation of $\mathrm{Mg}$ colloids starts already after preheating of the irradiated sample to $513 \mathrm{~K}$ and continues at heating to $613 \mathrm{~K}$ [see Fig. 6(b)]. The absorption bands related to other defects are annealed after a preheating to $753 \mathrm{~K}$, while the band attributed to a magnesium colloid is clearly detected [Fig. 6(a)].

Figure 7 presents the curves of thermally stimulated luminescence for the LiF crystals previously irradiated at RT by $2.187-\mathrm{GeV} \mathrm{Au}$ ions $\left(\Phi=4 \times 10^{10} \mathrm{ions} / \mathrm{cm}^{2}\right)$ and kept in darkness for several months. The main TSL peak at $565 \mathrm{~K}$ can be separated by the preheating of the identically irradiated sample to $513 \mathrm{~K}$. The annealing of the IOA related to $F$, $F_{2}$, and $F_{3}$ centers as well as the rise of a weak absorption at

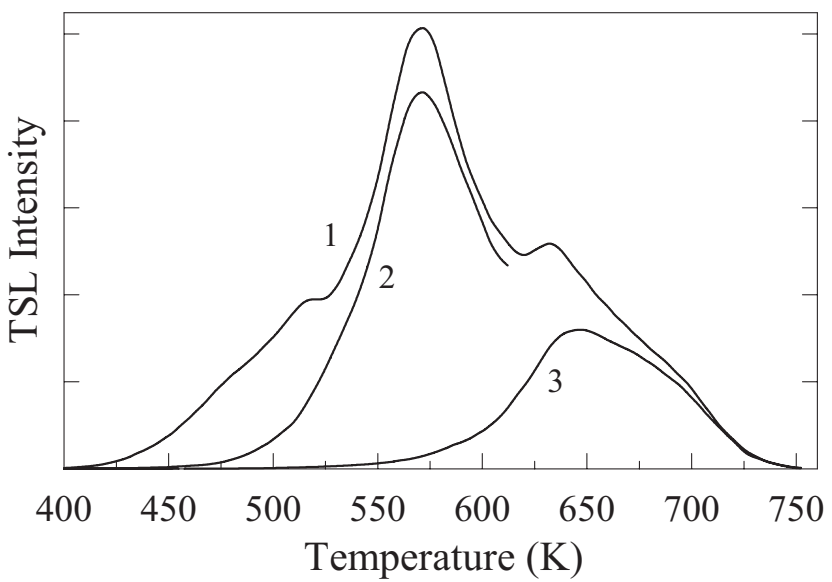

FIG. 7. Integral thermally stimulated luminescence measured for a $\mathrm{LiF}$ crystal irradiated with $2.187-\mathrm{GeV}$ gold ions $\left(\Phi=4 \times 10^{10}\right.$ ions $\left./ \mathrm{cm}^{2}\right)$ at RT (curve 1$)$. TSL curves measured after an additional preheating of the irradiated sample to $513 \mathrm{~K}$ (curve 2) or $613 \mathrm{~K}$ (curve 3 ). The heating rate $\beta=2.86 \mathrm{~K} \mathrm{~s}^{-1}$.

$3.6-4.6 \mathrm{eV}$ occur in the temperature range of $513-613 \mathrm{~K}$ (see Fig. 6). The TSL was measured up to $613 \mathrm{~K}$, then the crystal was rapidly cooled down to RT, and the measurement of TSL was repeated up to $753 \mathrm{~K}$. Nonelementary hightemperature TSL consists of several peaks. An additional precise investigation of TSL at $580-740 \mathrm{~K}$ allowed us to separate the elementary peaks at 630 and $685 \mathrm{~K}$ and a weak one at $725 \mathrm{~K}$.

The creation of luminescent $F_{2}$ centers at RT by photons of $h \nu \geqslant E_{g}=14.2 \mathrm{eV}$ was investigated in LiF long ago, and the electron-hole transformation mechanism of $F$ into $F_{2}$ centers was proposed. ${ }^{32}$ This transformation involves the joining of an anion vacancy to an $F$ center with the formation of $F_{2}{ }^{+}$and the subsequent trapping of a conduction electron via an excited state of an $F_{2}$ center. Finally, the transition to a ground state with the $1.85 \mathrm{eV}$ emission leads to the formation of a stable $F_{2}$ center. The theoretical calculations of other possible transformations of $F$ centers into $F_{2}$ or $F_{3}$ centers at sufficiently high temperature in additively colored $\mathrm{NaCl}$ and $\mathrm{KCl}$ crystals were performed in Ref. 29. At a high temperature, a part of $F$ centers becomes ionized and mobile anion vacancies participate in the formation of $F_{2}$ centers (via a trapping of an electron by $\mathrm{F}_{2}{ }^{+}$).

In $\mathrm{LiF}$ irradiated with $5-\mathrm{MeV} \mathrm{Au}$ ions $(\Phi$ $=10^{14}$ ions $/ \mathrm{cm}^{2}$ ), the intensity of the IOA band at $2.3-3.4 \mathrm{eV}$ ascribed to lithium colloids increases with a heating of the sample from 513 to $613 \mathrm{~K}$ and then decreases at $613-753 \mathrm{~K}$ (see Fig. 3). Figure 8 shows an integral TSL curve measured for the same irradiated LiF sample in the whole temperature range of $300-753 \mathrm{~K}$ with a constant rate of $\beta=2.86 \mathrm{~K} \mathrm{~s}^{-1}$. The TSL intensity for a LiF crystal irradiated with $5-\mathrm{MeV} \mathrm{Au}$ ions $(R=1.1 \mu \mathrm{m})$ is by several orders of magnitude lower than that for the crystal irradiated with $2.187-\mathrm{GeV}$ ions $\left(\Phi=4 \times 10^{10} \mathrm{Au} / \mathrm{cm}^{2}, R=92.0 \mu \mathrm{m}\right)$. Figure 8 also presents the TSL curves measured after a preheating of $5-\mathrm{MeV}$ ion irradiated $\mathrm{LiF}$ to $513 \mathrm{~K}$ (curve 2, measured up to $613 \mathrm{~K}$ ) and $613 \mathrm{~K}$ (curve 3). The latter curve carries information on the thermal annealing of a broadband IOA of 


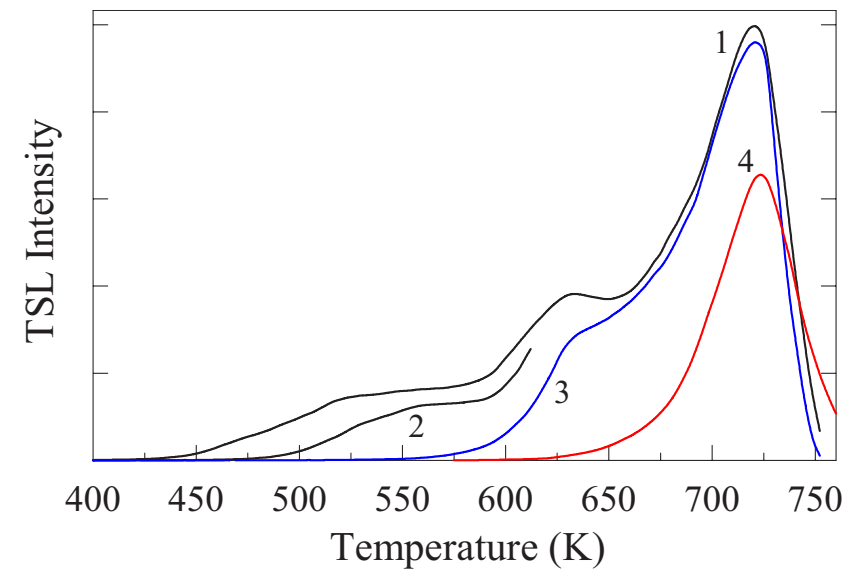

FIG. 8. (Color online) Integral TSL measured for LiF crystals irradiated with $5-\mathrm{MeV} \mathrm{Au}$ ions at $\Phi=10^{14}$ ions $/ \mathrm{cm}^{2}$ and $i_{\text {beam }}=120 \mathrm{nA}$ (curves $1-3$ ) or $i_{\text {beam }}=200 \mathrm{nA}$ (curve 4). The TSL curves were measured with a constant heating rate $\beta=2.86 \mathrm{~K} \mathrm{~s}^{-1}$ in the whole range of 300-753 $\mathrm{K}$ (curve 1) or after a preheating of the irradiated sample to $513 \mathrm{~K}$ (curve 2, measured up to $613 \mathrm{~K}$ ), to $613 \mathrm{~K}$ (curve 3), and to $693 \mathrm{~K}$ (curve 4).

lithium colloids and has been quantitatively analyzed by decomposition into the components described by first order kinetics. The activation energies $\varepsilon$ and frequency factors $p$ that characterize TSL elementary peaks have been determined. The TSL contains the peaks with the maxima at $630 \mathrm{~K}\left(\varepsilon_{1}\right.$ $\left.=2.19 \mathrm{eV}, p_{1}=5 \times 10^{16} \mathrm{~s}^{-1}\right), \quad 665 \mathrm{~K}\left(\varepsilon_{2}=1.58 \mathrm{eV}, p_{2}\right.$ $\left.=10^{11} \mathrm{~s}^{-1}\right)$, and $720 \mathrm{~K}\left(\varepsilon_{3}=2.49 \mathrm{eV}, p_{3}=5 \times 10^{16} \mathrm{~s}^{-1}\right)$. In the region of the efficient thermal destruction of lithium colloids (660-670 K), a low value of $p_{2}$, compared to the threshold frequency of lattice vibrations $\left(\sim 10^{14} \mathrm{~s}^{-1}\right)$, tentatively testifies that a mobile partner (e.g., an $H$ interstitial) should perform many hops before its radiative recombination with the localized partner. The highest-temperature nonelementary TSL peak at $720 \mathrm{~K}$ is clearly observed after a preheating of a hardly irradiated $\mathrm{LiF}$ crystal $\left(\Phi=10^{14} \mathrm{Au} / \mathrm{cm}^{2}, \quad i_{\text {beam }}\right.$ $=200 \mathrm{nA}$ ) up to $693 \mathrm{~K}$ (Fig. 8, curve 4). Notice that $T$ $=720 \mathrm{~K}=0.64 T_{\text {melt }}\left(T_{\text {melt }}=1120 \mathrm{~K}\right.$ is the melting temperature of $\mathrm{LiF}$ ). In nonirradiated LiF crystals containing about $1 \mathrm{ppm}$ of $\mathrm{Mg}^{2+}$ impurity ions, the temperature dependence of ionic conductivity in this temperature range is typical of intrinsic conductivity. ${ }^{33}$ In our opinion, new thermallyinduced point defects can facilitate a total annealing of nanosize lithium colloids.

\section{DISCUSSION}

\section{A. Extrinsic and intrinsic colloids in $\mathrm{LiF}$}

Electron color centers (neutral $F, F_{2}, F_{3}$, and $F_{4}$ as well as charged $\mathrm{F}^{\prime}, \mathrm{F}_{2}{ }^{+}, \mathrm{F}_{2}{ }^{-}, \mathrm{F}_{3}{ }^{+}$, and $\mathrm{F}_{3}{ }^{-}$) were thoroughly investigated in LiF crystals irradiated by $\mathrm{x}$ and $\gamma$ rays, electrons, $\alpha$ particles as well as light and heavy swift ions (see Refs. 22 and 29, and references therein). In the present study, the spectra of IOA have been measured in LiF crystals irradiated at RT by $5-10 \mathrm{MeV}$ heavy ions (gold) with different fluences and fluxes. At low irradiation fluences, the absorption

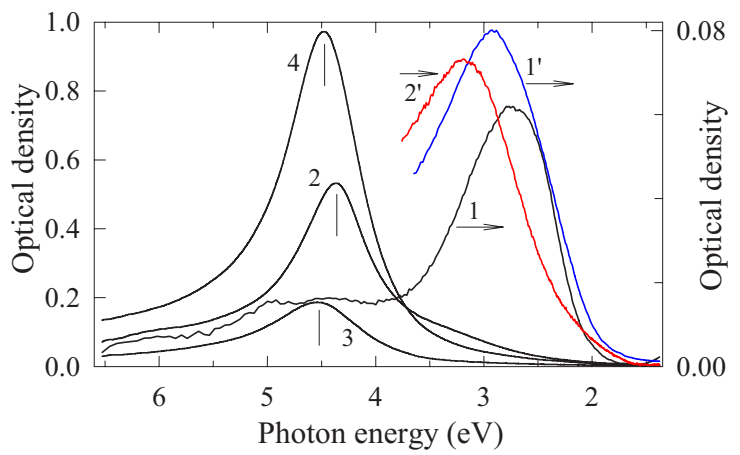

FIG. 9. (Color online) Broadband absorption related to two types of nanosize metallic colloids in LiF crystals irradiated with swift heavy ions at RT. Irradiation conditions: curves 1 and 1', $5-\mathrm{MeV} \mathrm{Au}$ ions, $\Phi=10^{14}$ ions $/ \mathrm{cm}^{2}$, and $i_{\text {beam }}=200 \mathrm{nA}$; curves 2 and $2^{\prime}, 10-\mathrm{MeV}$ Au ions, $\Phi=2 \times 10^{14} \mathrm{ions} / \mathrm{cm}^{2}$, and $i_{\text {beam }}=100 \mathrm{nA} ; \quad$ curve $3,2.187-\mathrm{GeV} \mathrm{Au}$ ions and $\Phi=4 \times 10^{10}$ ions $/ \mathrm{cm}^{2}$; curve $4,1.404-\mathrm{GeV} \quad \mathrm{U}$ ions and $\Phi=3 \times 10^{11}$ ions $/ \mathrm{cm}^{2}$. The absorption spectra were measured after preheating of the irradiated sample to $753 \mathrm{~K}$ (curves 2-4). Decrease of radiation-induced absorption caused by a heating of the irradiated crystal from 653 to $693 \mathrm{~K}$ (curve 1), from 693 to $753 \mathrm{~K}$ (curve $1^{\prime}$ ), or from 723 to $753 \mathrm{~K}$ (curve $2^{\prime}$ ). All spectra are measured at $\mathrm{RT}$, the heating rate is $\beta=2.86 \mathrm{~K} \mathrm{~s}^{-1}$.

spectra contain the bands attributed to $F$ centers (half-width of $0.79 \mathrm{eV}$ ) as well as to $F_{2}, F_{3}$, and $F_{4}$ centers with halfwidths of $0.15-0.20 \mathrm{eV}$. At high fluences and fluxes, a preheating of an irradiated sample to 513,613 , or $693 \mathrm{~K}$ enables one to separate the more complex centers responsible for two broad absorption (extinction) bands with half-widths of about $1 \mathrm{eV}$ (see Fig. 9 and Sec. III). The shapes of these bands cannot be described by Gaussians typical of many point defects in ionic crystals with a strong electron-phonon interaction. We failed to detect any characteristic emission (with a large Stokes shift) at the photoexcitation of the irradiated samples in the region of broad absorption bands even at $6 \mathrm{~K} .{ }^{34}$ In contrast to $F, F_{2}$, and $F_{3}$ bands, a cooling of $\mathrm{LiF}$ down to $80-250 \mathrm{~K}$ does not cause a narrowing of the absorption band related to the colloids formed at high temperatures. According to our experimental data, the position of the maximum of broadband IOA depends on the size of complex defects and shifts toward a high-energy region with a decrease in the defect size. In our opinion, two broad bands with maxima at 4.2-4.6 and 2.7-3.1 eV are connected with two types of metallic colloids formed due to the irradiation of $\mathrm{LiF}$ with gold ions at RT. The shape of the $4.43 \mathrm{eV}$ absorption band is not changed by cooling from RT to $8 \mathrm{~K}$.

Metallic colloids have been studied long ago in many alkali halide crystals, especially thoroughly in the so-called additively colored crystals. At additive coloration (thermochemical reduction), a crystal is heated in the alkali metal vapor at high temperature, the excess metal is introduced into the crystal, and a high concentration of $F$ centers is produced. A subsequent heating of the additively colored alkali halide crystal leads to coagulation of $F$ centers with the formation of metallic particles (colloids), the size of which varies over a wide range. Unfortunately, in spite of repeated attempts (see, e.g., Ref. 35), the additive coloration of LiF 
crystals has not been successful yet. At the same time, already the first experiments with $\mathrm{LiF}$ single crystals irradiated with high doses of thermal neutrons in a nuclear reactor showed that, in addition to $F, F_{2}, F_{3}$, etc., single centers, more complex centers responsible for light scattering and broadband absorption are also formed at increasing neutron fluence (see, e.g., reviews ${ }^{36-38}$ ). At the first stage, an efficient interaction of a thermal neutron with a ${ }^{6} \mathrm{Li}$ nucleus causes the formation of helium and tritium nuclei (with a kinetic energy of 2.7 and $2.1 \mathrm{MeV}$, respectively), which produce different electronic excitations responsible for the formation of radiation defects in LiF.

The colloids with the absorption at $4.2-4.6 \mathrm{eV}$ were revealed long ago in nominally pure $\mathrm{LiF}$, which undoubtedly contained $\mathrm{Mg}^{2+}$ ions located at lithium lattice sites as well as cation vacancies for charge compensation. A wide absorption band peaked at $\sim 4.4-4.6 \mathrm{eV}$ was detected in $\mathrm{LiF}$ after a prolonged irradiation by $\mathrm{x}$ rays, mixed gamma-neutron fields, or swift heavy and light ions. ${ }^{37-39}$ Impurity nanosize magnesium colloid was studied most thoroughly in LiF crystals with low and high $(\sim 2000 \mathrm{ppm})$ concentrations of $\mathrm{Mg}^{2+}$ impurity ions exposed at RT to neon, argon, or magnesium ions $\left(\Phi=10^{16}\right.$ ions $\left./ \mathrm{cm}^{2}\right) .{ }^{30}$ The $\mathrm{Mg}$ colloid band at $4.43 \mathrm{eV}$ $(280 \mathrm{~nm})$ was detected in doped LiF crystals after irradiation with $100-\mathrm{keV}$ Ar ions. In $\mathrm{LiF}$ irradiated with $\mathrm{Mg}$ ions and preheated to $770 \mathrm{~K}$, a short-wavelength band with a maximum at $4.6 \mathrm{eV}$ was attributed to nanosize $\mathrm{Mg}$ colloids. A weak band $(\sim 4.47 \mathrm{eV})$ connected with similar colloids is clearly observed in our LiF crystals irradiated at RT by $2.187-\mathrm{GeV} \mathrm{Au}$ ions with a low fluence $\left(\Phi=4 \times 10^{10}\right.$ ions $\left./ \mathrm{cm}^{2}\right)$ and preheated to $753 \mathrm{~K}$ with $\beta=2.86 \mathrm{~K} \mathrm{~s}^{-1}$ (see Fig. 9, curve 3). According to our data, the intensity of the $4.45 \mathrm{eV}$ band is higher in the crystal irradiated by $1.42 \mathrm{GeV}{ }^{238} \mathrm{U}$ ions $\left(\Phi=3 \times 10^{11}\right.$ ions $\left./ \mathrm{cm}^{2}\right)$ and heat treated (curve 4). The energy losses of $\mathrm{Au}$ and $\mathrm{U}$ ions with kinetic energies above $1 \mathrm{GeV}$ are almost entirely determined by the ionization and/or excitation of LiF lattice ions by heavy swift ions. So, the overlapping of the crystal regions, where $\delta$ electrons are formed, in the case of uranium ion irradiation (the distance between single tracks is about $d=18 \mathrm{~nm})$ is significantly higher than that in the case of $\mathrm{Au}$ ion irradiation $\left(\Phi=4 \times 10^{10}\right.$ ions $\left./ \mathrm{cm}^{2}, d=56.5 \mathrm{~nm}\right)$. Our LiF samples contain about $20 \mathrm{ppm}$ of $\mathrm{Mg}^{2+}$ impurity ions. In $\mathrm{LiF}$ irradiated with $10-\mathrm{MeV}$ Au ions $\left(\Phi=2 \times 10^{14} \mathrm{ions} / \mathrm{cm}^{2}\right)$ and rapidly preheated to $753 \mathrm{~K}$, a colloid band has a maximum at $4.37 \mathrm{eV}$ at RT (Fig. 9, curve 2). We have obtained additional proofs of the connection of IOA band at 4.4-4.6 eV with impurity (magnesium) colloids and not with intrinsic ones by investigating $\mathrm{LiF}$ crystals doped with a precisely determined concentration of $\mathrm{Mg}$ ions (100 ppm). $\mathrm{Mg}^{2+}$ substitutes for $\mathrm{Li}^{+}$in a regular lattice site, while a cation vacancy serves as a charge compensator. The intensity of the colloid-related IOA band in LiF:Mg irradiated with uranium ions (2.25 GeV, $\Phi=10^{11}$ ions $/ \mathrm{cm}^{2}$, and $\varphi=10^{8} \mathrm{ions} / \mathrm{cm}^{2} \mathrm{~s}$ ) and preheated to $753 \mathrm{~K}$ was three times as high as that in our main LiF samples under the same irradiation conditions.

In highly pure LiF crystals, intrinsic Li colloids are not experimentally studied in detail, while metallic colloids are thoroughly investigated in other alkali halide crystals, espe- cially in additively colored crystals with a high concentration of $F$ centers. Intrinsic lithium colloid can be created in $\mathrm{LiF}$ only under particularly favorable irradiation conditions. In $\mathrm{LiF}$, the $\mathrm{Li}$ sublattice constant is much smaller than that in free lithium metal (the difference in the volume of the unit cell is as big as 25\%). ${ }^{39}$ So, the formation of intrinsic $\mathrm{Li}$ colloid is hampered. After its formation in a crystal bulk, a colloid turns out to be in a compressed state and its optical characteristics drastically differ from those for large-size regions of metallic lithium at the crystal surface formed at high-fluence irradiation of LiF by thermal neutrons. ${ }^{36-38}$ The optical characteristics of spherical intrinsic Li colloids with a radius $r_{\text {col }}$ of up to $90 \mathrm{~nm}$ were calculated using the modified Mie theory. ${ }^{40}$ According to these calculations, a maximum of Li colloid extinction band is shifted toward lower energies with increasing $r_{\text {col }}: 2.73 \mathrm{eV}$ for the smallest colloid, $2.56 \mathrm{eV}$ for $r_{\mathrm{col}}=20 \mathrm{~nm}$, and $2.44 \mathrm{eV}$ for $r_{\mathrm{col}}=30 \mathrm{~nm}$.

Unfortunately, real intrinsic Li colloid in LiF cannot be considered as spherical particles and have a platelet morphology (along $\{100\}$ planes). ${ }^{29,41}$ Thus the optical characteristics of real intrinsic Li colloid significantly differ from the calculated ones. A further theoretical analysis of the peculiarities of the optical characteristics of Li colloids (see Sec. III and Fig. 9) lies ahead.

Figure 9 presents the decrease of IOA that occurs at the annealing from 653 to $693 \mathrm{~K}$ (curve 1) and from 693 to $753 \mathrm{~K}$ (curve $1^{\prime}$ ) measured for a LiF crystal irradiated by $5-\mathrm{MeV}$ Au ions $\left(\Phi=10^{14}\right.$ ions $\left./ \mathrm{cm}^{2}, i_{\text {beam }}=200 \mathrm{nA}\right)$. The maximum of a broad IOA band undergoes transformation in the position of $2.8-2.93 \mathrm{eV}$. The intensity of IOA at $2.2-3.5 \mathrm{eV}$, associated with intrinsic colloids, decreases in the temperature range of 653-693 $\mathrm{K}$ and a total annealing of this band takes place at $693-753 \mathrm{~K}$. A band maximum position in the difference spectrum of IOA annealed at $693-753 \mathrm{~K}$ is shifted toward higher energies, in accordance with the decreasing size of lithium colloids. In a LiF crystal, irradiated by $10-\mathrm{MeV} \mathrm{Au}$ ions $\left(\Phi=2 \times 10^{14} \mathrm{ions} / \mathrm{cm}^{2}\right)$, a maximum of IOA, annealed in the final stage at $723-753 \mathrm{~K}$ and attributed to lithium colloids with the size of a few nanometers, is located at $\sim 3.2 \mathrm{eV}$ (curve $2^{\prime}$ ). For this case, following the theory, the decrease of colloid size again is accompanied by the shift of a maximum of colloid-related absorption band toward a short-wavelength spectral region.

It should be noted that, according to the recent review paper on colloids in alkali halides by Kotomin and Popov, ${ }^{29}$ intrinsic Li colloids in irradiated $\mathrm{LiF}$ crystals are responsible for the absorption band peaked at $2.76 \mathrm{eV}$, while the bands at 2.38 and $1.82 \mathrm{eV}$ are attributed to the impurity sodium and potassium colloids, respectively. On the other hand, the band with a maximum at $4.34 \mathrm{eV}$ (i.e., at significantly higher energy) is ascribed to intrinsic $\mathrm{Mg}$ colloids in $\mathrm{MgF}_{2}$ crystals. $^{29,31}$ On this basis, the separation of intrinsic and impurity metallic colloids in nominally pure LiF crystals is of critical importance.

\section{B. About formation mechanisms of intrinsic colloids}

In the present study, it is shown that the creation efficiency of intrinsic lithium colloids depends on both the flu- 
ence and the flux of the 5-10 MeV gold ions used to accumulate high values of $\Phi$. The efficiency of Li colloid creation at the accumulation of the fluence of $\Phi \sim 10^{14}$ ions $/ \mathrm{cm}^{2}$ with a low flux $\left(i_{\text {beam }}=5-10 \mathrm{nA}\right)$ is several times lower than that for the same fluence reached with a high flux ( $\left.i_{\text {beam }}=50-120 \mathrm{nA}\right)$. Relying on these data, it is possible to discuss the distinguishing peculiarities of the processes of colloid creation in LiF crystals.

As was already mentioned in Sec. III A, the situation in $\mathrm{LiF}$ is formally similar to the effect discovered long ago in classic photographic materials-silver halides. ${ }^{24-26}$ In AgBr:I at RT, one exciting photon creates a single interstitial silver atom and a stable center of latent image is not formed in the case of low intensities. The stable center, consisting of three to four spatially close Ag atoms, can be easily formed at a high illumination intensity or by $\sim 10-\mathrm{eV}$ photons, each of which is able to create three to four $e-h$ pairs. ${ }^{24,26}$ The center of a latent image undergoes transformation into a large colloid particle during the development of a photographic image. To understand the reasons of the reciprocity law failure between the intensity and duration of irradiation in $\mathrm{LiF}$ in the case of low fluxes (long irradiation time), it should be taken into account that the hopping diffusion of $H$ interstitials (interstitial fluorine atoms) starts already at $50-60 \mathrm{~K} \cdot{ }^{5,7,8}$ The recombination of $H$ centers with $F$ and $F_{2}$ centers, which are immobile at RT, causes the restoration of a regular lattice. On the other hand, it is shown ${ }^{7,23}$ that a pair association of two $H$ interstitials in the form of a trihalide molecule is stable at RT, thus, providing the existence of two $F$ centers $(F$ and $H$ centers are created in the form of $F-H$ pairs of complementary defects). Just such a pair association can serve as seeds for nanosize radiation defects (including metallic colloids). Unfortunately, at 500-560 K, these trihalide molecules dissociate into $H$ interstitials, which are highly mobile and undergo recombination with $F$ and $F_{2}$ centers. The seeds stable at $560-620 \mathrm{~K}$, when the decay of $F_{3}$ and more complex defects takes place, should provide an efficient creation of intrinsic Li colloids in this temperature range. In our opinion, two or more spatially close $F_{3}$ centers can fulfill the role of such a seed. The creation of spatially correlated $F_{3}$ centers is eliminated at low fluences and fluxes, and has a low probability in the case of a high fluence but a low flux. However, the favorable conditions for the creation of agglomerates of $F_{3}$ centers arise under the crystal irradiation with both high fluence and high flux, when the probability of repeated hits of bombarding ions into the crystal regions with already created $F_{3}$ centers gets high enough.

We have observed the formation of lithium colloids and their enlargement at a subsequent heating in LiF crystals irradiated at RT with $5-\mathrm{MeV}$ and, especially, $10-\mathrm{MeV}$ Au ions if a fluence of $\Phi \sim 10^{14}$ ions $/ \mathrm{cm}^{2}$ (the mean distance between ion tracks is $d=1.1 \mathrm{~nm}$ ) was accumulated within several minutes. According to our estimates, such irradiation regime provides multiple covering of nanosize regions with $F, F_{2}$, and $F_{3}$ centers created by $\delta$ electrons, which in turn were formed directly by bombarding gold ions or by the displaced lithium and fluorine ions. The maximum energy of $\delta$ electrons formed by $10-\mathrm{MeV}$ gold ions is about $100 \mathrm{eV}$, i.e., is sufficient for the excitation (exciton formation) of both anions and cations, while for $5-\mathrm{MeV}$ ions the maximum energy of $\delta$ electrons is only about $\sim 50-60 \mathrm{eV}$, and the creation of cation excitons $(\sim 62 \mathrm{eV})$ by these electrons is less probable. It should be mentioned that a relatively low energy of $\delta$ electrons in the case of $5-\mathrm{MeV}$ Au irradiation leads to the formation of electronic excitations only within a small region along the ion path. According to our experimental data, the saturation of the number of $F$ centers created by $5-\mathrm{MeV}$ ions is detected at $\Phi=8 \times 10^{13}$ ions $/ \mathrm{cm}^{2}$, and it can be estimated that $F$ centers are created within the tracks with a radius of $r_{F} \approx 1 \mathrm{~nm}$. If $r_{F}=1 \mathrm{~nm}$ and using the procedure described in Refs. 11 and 13, we can conclude that there is no overlapping of gold ion tracks at the irradiation of $\mathrm{LiF}$ with $\Phi=5 \times 10^{12}$ ions $/ \mathrm{cm}^{2} \quad(d=5.1 \mathrm{~nm})$, while the overlapping of colored regions takes place at $\Phi=8 \times 10^{13}$ ions $/ \mathrm{cm}^{2}(d=1.3 \mathrm{~nm})$.

The irradiation of $\mathrm{LiF}$ crystals with $10-\mathrm{MeV} \mathrm{Au}$ ions causes a high creation efficiency of intrinsic Li colloids because the following two conditions are fulfilled: $\delta$ electrons efficiently form cation excitons and the irradiated crystal surface is multicovered by colored regions (repeated hits of gold ions into the same crystal regions). It has been shown recently ${ }^{5,6}$ that the decay of cation excitons (selectively formed by $62 \mathrm{eV}$ photons) in $\mathrm{LiF}$ leads to the creation of an anion exciton $(\sim 13 \mathrm{eV})$, while the rest of the energy $(\sim 49 \mathrm{eV})$, after intermediate processes, is transformed into three electron-hole pairs. As a result, a group of spatially correlated point defects can be created from the group of electronic excitations (an exciton and three $e-h$ pairs). The transformation of such group of electronic excitations into a group of three or even more stable point defects has been detected only at $5-14 \mathrm{~K} .^{5,6}$ The investigation of the decay products of cation excitons at the irradiation of $\mathrm{LiF}$ with different fluxes at RT still lies ahead.

As noted above, the formation efficiency of cation excitons at the irradiation of $\mathrm{LiF}$ with $5-\mathrm{MeV} \mathrm{Au}$ ions is rather low (the energy of $\delta$ electrons does not exceed $50-60 \mathrm{eV}$ ), which results in a low probability of the creation of the groups of spatially correlated electronic excitations and point defects. According to our experimental data (see Sec. III B and Fig. 9), the creation efficiency of Li colloids in LiF by $5-\mathrm{MeV}$ gold ions is lower than that by $10-\mathrm{MeV}$ Au ions. The energy of $\delta$ electrons formed at the irradiation of LiF with $1.4-\mathrm{GeV} \mathrm{U}$ ions $\left(R=92 \mu \mathrm{m}, \Phi=3 \times 10^{11} \mathrm{ions} / \mathrm{cm}^{2}\right)$ is significantly higher than that in the case of $5-10 \mathrm{MeV}$ gold ions. Thus a strong overlapping of the regions excited by $\delta$ electrons from neighboring bombarding ions takes place even at a relatively large distance between these tracks $(d=20.6 \mathrm{~nm})$ and explains the fact that the number ratio of $F_{2}$ and $F$ centers created under such irradiation conditions is higher than that at $\Phi=4 \times 10^{10}$ ions $/ \mathrm{cm}^{2}(d=56.5 \mathrm{~nm})$, when there is practically no overlapping of neighboring ion tracks (this effect was thoroughly investigated in Ref. 11).

It is significant that impurity $\mathrm{Mg}$ colloids are detected in our $\mathrm{LiF}\left(\sim 20 \mathrm{ppm}\right.$ of $\left.\mathrm{Mg}^{2+}\right)$ and LiF:Mg (100 ppm) crystals irradiated with $1-2.5 \mathrm{GeV}$ heavy ions $\left(\Phi=10^{11}-10^{12}\right.$ ions $/ \mathrm{cm}^{2}, \varphi=10^{8}$ ions $\left.\mathrm{cm}^{-2} \mathrm{~s}^{-1}\right)$ and preheated to 653 or $753 \mathrm{~K}$. However, we succeeded in detecting intrinsic Li colloids only after similar irradiation with a high fluence of $\Phi=10^{13}$ ions $/ \mathrm{cm}^{2}$ ( $d=3.6 \mathrm{~nm}$, multiple covering 
by colored regions), i.e., close to the threshold for the radiation cracks of a LiF crystal. ${ }^{42}$ The radiation-induced formation of large cracks has been investigated in detail in $\mathrm{NaCl}$ crystals with a lower radiation resistance (compared to $\mathrm{LiF}){ }^{43}$

Unfortunately, in the context of the present study, we have not managed to determine the contribution of nuclear energy losses of 5-10 MeV Au ions to the formation of nanosize intrinsic Li colloids. A further investigation of optical characteristics of $\mathrm{LiF}$ crystals, ion-irradiated at room or higher temperatures, is needed in a wider spectral region (up to $16-18 \mathrm{eV}$, including measurement at helium temperatures). It is necessary to determine the excitation regions of fluorine ions located near single anion or cation vacancies and their associations.

\section{CONCLUSION}

The damage creation in LiF crystals under irradiation with 5-10 MeV Au ions significantly differs from the thoroughly studied processes of defect creation by $\mathrm{GeV}$ ions. Due to the low energy and the small range of $\delta$ electrons formed by $\mathrm{MeV}$ gold ions, the creation efficiency of color centers $\left(F, F_{n}\right)$ and colloids drastically depends also on the ion flux (beam current) used to accumulate a certain fluence above a critical value.

An especially noticeable rise of the creation efficiency for the aggregates of $F$ centers $\left(F_{2}, F_{3}\right.$, and $\left.F_{4}\right)$ and intrinsic lithium colloids is observed if a high fluence is accumulated with a high flux of 5-10 MeV gold ions. Particularly favorable conditions for the formation of nanosize intrinsic $\mathrm{Li}$ colloids are realized at the irradiation of LiF crystals with $10-\mathrm{MeV}$ Au ions $\left(\Phi=10^{14}\right.$ ions $\left./ \mathrm{cm}^{2}, i_{\text {beam }}=120 \mathrm{nA}\right)$, which form $\delta$ electrons with an energy of $\sim 100 \mathrm{eV}$. These $\delta$ electrons efficiently create localized cation excitons $(\sim 62 \mathrm{eV})$, each of which decays at RT with the formation of three to four spatially correlated $F$ centers and highly mobile $H$ interstitials escaping from this crystal region. At a high ion flux, the next bombarding ion can hit the same crystal region with a small time delay $(\sim 10-100 \mathrm{~s})$ and forms, after similar intermediate processes, the second group of $F$ centers. $F$ centers from the groups created at repeated hits of Au ions in the same crystal region form thermally stable agglomerates of several $F_{3}$ or even more complex centers, which serve as stable seeds for colloid formation. Intrinsic Li colloids increase in size at a heating of the irradiated sample to $\sim 600 \mathrm{~K}$. The annealing of Li colloids occurs in the temperature range of $630-730 \mathrm{~K}$ and is accompanied by the decrease of colloids in size (down to several nanometers) and a shift of the maximum of colloid-related absorption band from 2.74 to $3.3 \mathrm{eV}$.

The revealed peculiarities of the defect aggregate and intrinsic $\mathrm{Li}$ colloid formation under 5-10 MeV Au ion irradiation in LiF crystals are analogous to the reciprocity law failure at a low illumination intensity for classic photographic materials based on silver halides.

\section{ACKNOWLEDGMENTS}

This work has been supported by the Estonian Science Foundation (Grant No. 6652) and the European CommunityResearch Infrastructure Action under the FP6 "Structuring the European Research Area" program (through the Integrated Infrastructure Initiative "Integrating Activity on Synchrotron and Free Electron Laser Science"). Financial support from Russian Fund for Basic Research (Grants No. 0502-16994 and No. 06-08-81030) and INTAS (05-111-5118) is gratefully acknowledged by M.V.S. and A.E.V.
${ }^{1}$ K. S. Song and R. T. Williams, Self-Trapped Excitons, 2nd ed. (Springer-Verlag, Berlin, 1996).

${ }^{2}$ Ch. Lushchik and A. Lushchik, Decay of Electronic Excitations with Defect Formation in Solids (Nauka, Moscow, 1989).

${ }^{3}$ Ch. B. Lushchik, in Physics of Radiation Effects in Crystals, edited by R. A. Johnson and A. N. Orlov (North-Holland, Amsterdam, 1986), Chap. 8.

${ }^{4}$ A. Lushchik, M. Kirm, Ch. Lushchik, and E. Vasil'chenko, Nucl. Instrum. Methods Phys. Res. B 166-167, 529 (2000).

${ }^{5}$ S. Nakonechnyi, T. Kärner, A. Lushchik, Ch. Lushchik, V. Babin, E. Feldbach, I. Kudryavtseva, P. Liblik, L. Pung, and E. Vasil'chenko, J. Phys.: Condens. Matter 18, 379 (2006).

${ }^{6}$ A. Lushchik, Ch. Lushchik, M. Kirm, V. Nagirnyi, F. Savikhin, and E. Vasil'chenko, Nucl. Instrum. Methods Phys. Res. B 250, 330 (2006).

${ }^{7}$ E. Vasil'chenko, I. Kudryavtseva, A. Lushchik, Ch. Lushchik, and V. Nagirnyi, Phys. Status Solidi C 2, 405 (2005).

${ }^{8}$ Y. H. Chu and R. L. Mieher, Phys. Rev. 188, 1311 (1969).

${ }^{9}$ E. Balanzat, S. Bouffard, A. Cassimi, E. Dooryhee, J. P. Grandin, J. L. Doualan, and J. Margerie, Nucl. Instrum. Methods Phys. Res. B 91, 134 (1994).
${ }^{10}$ K. Schwartz, A. E. Volkov, K.-O. Voss, M. V. Sorokin, C. Trautmann, and R. Neumann, Nucl. Instrum. Methods Phys. Res. B 245, 204 (2006).

${ }^{11}$ K. Schwartz, C. Trautmann, A. S. El-Said, R. Neumann, M. Toulemonde, and W. Knolle, Phys. Rev. B 70, 184104 (2004).

${ }^{12}$ C. Trautmann, K. Schwartz, J. M. Costantini, T. Steckenreiter, and M. Toulemonde, Nucl. Instrum. Methods Phys. Res. B 146, 367 (1998).

${ }^{13}$ K. Schwartz, C. Trautmann, T. Steckenreiter, O. Geiss, and M. Krämer, Phys. Rev. B 58, 11232 (1998).

${ }^{14}$ A. Perez, E. Balanzat, and J. Dural, Phys. Rev. B 41, 3943 (1990).

${ }^{15}$ J. F. Ziegler, M. D. Ziegler, and J. P. Biersack, SRIM 2006.02.

${ }^{16}$ B. Gervais and S. Bouffard, Nucl. Instrum. Methods Phys. Res. B 88, 355 (1994).

${ }^{17}$ R. Katz, Kim Sum Loh, Luo Daling, and Guo-Rong Huang, Radiat. Eff. Defects Solids 114, 15 (1990).

${ }^{18}$ P. Sigmund, Stopping of Heavy Ions (Springer, Heidelberg, 2004).

${ }^{19}$ M. Creuzburg, Z. Phys. 196, 433 (1966).

${ }^{20}$ J. R. Fields, P. C. Gibbons, and S. E. Schnatterly, Phys. Rev. Lett. 38, 430 (1977). 
${ }^{21}$ S. W. S. McKeever, M. Moscovitch, and P. D. Townsend, Thermoluminescence Dosimetry Materials: Properties and Uses (Nuclear Technology, Ashford, 1995).

${ }^{22}$ S. G. Baldacchini, J. Lumin. 100, 333 (2002).

${ }^{23}$ A. T. Davidson, K. Schwartz, J. D. Comins, A. G. Kozakiewicz, M. Toulemonde, and C. Trautmann, Phys. Rev. B 66, 214102 (2002).

${ }^{24}$ E. Katz, J. Chem. Phys. 18, 499 (1957).

${ }^{25}$ V. M. Belous, E. R. Ilmas, and N. S. Rooze, Sov. Phys. Solid State 11, 488 (1969).

${ }^{26}$ N. S. Rooze, Sov. Phys. Solid State 16, 1015 (1974).

${ }^{27}$ A. Lushchik, E. Feldbach, R. Kink, Ch. Lushchik, M. Kirm, and I. Martinson, Phys. Rev. B 53, 5379 (1996).

${ }^{28}$ A. Lushchik, I. Kudrjavtseva, C. Lushchik, E. Vasil'chenko, M. Kirm, and I. Martinson, Phys. Rev. B 52, 10069 (1995).

${ }^{29}$ E. A. Kotomin and A. I. Popov, in Radiation Effects in Solids, edited by K. E. Sickafus, E. A. Kotomin, and B. P. Uberuaga (Springer, Amsterdam, 2007), Chap. 7.

${ }^{30}$ A. T. Davidson, J. D. Comins, A. M. Raphuthi, A. G. Kozakiewicz, and T. E. Derry, J. Phys.: Condens. Matter 7, 3211 (1995).

${ }^{31}$ G. O. Amolo, J. D. Comins, A. T. Davidson, A. G. Kozakiewicz, T. E. Derry, and D. S. McLachlan, Nucl. Instrum. Methods Phys.
Res. B 218, 244 (2004).

${ }^{32}$ Yu. M. Aleksandrov, Ch. B. Lushchik, V. N. Makhov, T. I. Syreishchikova, and M. N. Jakimenko, Sov. Phys. Solid State 24, 968 (1982).

${ }^{33}$ T. G. Stoebe and S. Watanabe, Phys. Status Solidi A 29, 11 (1975).

${ }^{34}$ A. Lushchik, Ch. Lushchik, V. Nagirnyi, K. Schwartz, E. Vasil'chenko, A. Kotlov, and I. Kudryavtseva (unpublished).

${ }^{35}$ J. V. R. Kaufman and C. D. Klark, J. Chem. Phys. 38, 1388 (1963).

${ }^{36}$ J. J. Gilman and W. G. Johnson, J. Appl. Phys. 29, 877 (1958).

${ }^{37}$ N. G. Politov and L. F. Vorozheikina, Sov. Phys. Solid State 12, 277 (1970).

${ }^{38}$ C. Trautmann, K. Schwartz, and O. Geiss, J. Appl. Phys. 83, 3560 (1998).

${ }^{39}$ A. E. Hughes and S. C. Jain, Adv. Phys. 28, 717 (1979).

${ }^{40}$ I. S. Radchenko, Sov. Phys. Solid State 11, 1476 (1970).

${ }^{41}$ N. Bouchaala, E. A. Kotomin, V. N. Kuzovkov, and M. Reichling, Solid State Commun. 108, 629 (1998).

${ }^{42}$ I. Manika, J. Maniks, K. Schwartz, C. Trautmann, and M. Toulemonde, Phys. Status Solidi C 2, 434 (2005).

${ }^{43}$ V. I. Dubinko, A. A. Turkin, D. I. Vainstein, and H. W. den Hartog, Radiat. Eff. Defects Solids 156, 27 (2001). 